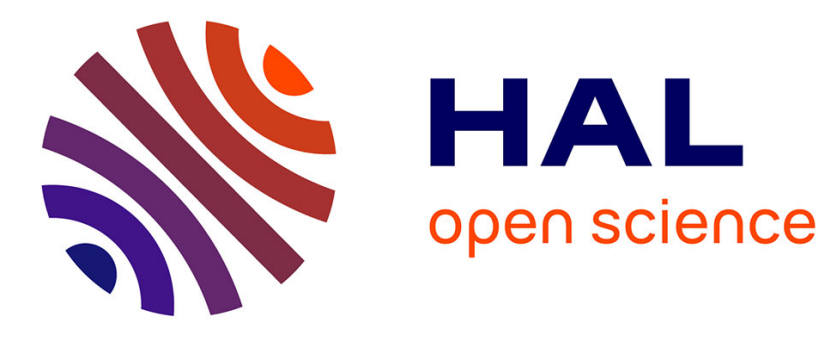

\title{
Bubble formation at an orifice: A multiscale investigation
}

N. Dietrich, Nadia Mayoufi, Souhila Poncin, Noël Midoux, Huai-Zhi Li

\section{To cite this version:}

N. Dietrich, Nadia Mayoufi, Souhila Poncin, Noël Midoux, Huai-Zhi Li. Bubble formation at an orifice: A multiscale investigation. Chemical Engineering Science, 2013, 92, pp.118-125. 10.1016/j.ces.2012.12.033 . hal-02050034

\section{HAL Id: hal-02050034 https://hal.science/hal-02050034}

Submitted on 22 Jul 2021

HAL is a multi-disciplinary open access archive for the deposit and dissemination of scientific research documents, whether they are published or not. The documents may come from teaching and research institutions in France or abroad, or from public or private research centers.
L'archive ouverte pluridisciplinaire HAL, est destinée au dépôt et à la diffusion de documents scientifiques de niveau recherche, publiés ou non, émanant des établissements d'enseignement et de recherche français ou étrangers, des laboratoires publics ou privés. 


\title{
Bubble formation at an orifice: a multiscale investigation
}

\author{
N. Dietrich, N. Mayoufi, S. Poncin, N. Midoux and Huai Z. Li* \\ Laboratory of Reactions and Process Engineering, Université de Lorraine, CNRS, \\ 1 rue Grandville, BP 20451, 54000 Nancy Cedex, France \\ *Corresponding author: Huai-Zhi.Li@ univ-lorraine.fr
}

\begin{abstract}
The formation of gas bubbles in a liquid is of both academic and industrial interest, and sets the initial conditions for the hydrodynamics, heat and mass transfer as well as chemical reactions from a dispersed gaseous phase to the liquid phase in industrial processes. The literature on bubble formation from a single submerged orifice is large in both Newtonian and non-Newtonian fluids. Despite the numerous theoretical and experimental investigations, the mechanisms of bubble growth and detachment remain far from fully understood. The study of bubble formation at microscale and especially in the presence of a lateral liquid flow field is still very limited. This is the topic for consideration in the present paper. In particular, this study compares both qualitatively and quantitatively the formation of bubbles at microand macroscales. A high-speed digital camera (up to 10000 images. $^{-1}$ ), a micro-Particle Image Velocimetry ( $\mu$-PIV) system and also a macro-PIV (PIV) were employed in this work, to measure the velocity flow field at micro- and macroscales. At macroscale, experiments were conducted in a square Altuglas column of $0.1 \mathrm{~m}$ filled with water or viscous Emkarox solutions using different orifice sizes and various gas flowrates. A rotating device above the orifice in the column was used to impose a shear flow on the forming bubble at the orifice. At microscale, different sizes of microreactors $(600$ and $1000 \mu \mathrm{m})$ and different microdevices were employed to compare the mechanism of bubble formation. A correlation based on
\end{abstract}


dimensionless numbers was proposed to estimate the formed bubble volume at micro- and macroscales in order to reveal the main factors governing the formation mechanisms.

Keywords: bubble formation, multiscale, lateral flow, PIV, $\mu-P I V$, flow measurements

\section{Introduction}

The earliest studies on the formation of a single bubble or drop have been published by Tate (1864) and Bashforth and Adams (1883). Bashforth and Adams calculated the shape of liquid menisci under equilibrium conditions and published their results in the form of tables. From their data, the evolution of bubbles can be calculated in the quasi-steady regime. Different models of various complexity including viscous and inertial forces have been proposed. Davidson \& Schüler (1960a) and Davidson \& Schüler (1960b) introduced models for dynamical bubble formation at submerged orifices for the case of both inviscid and viscous liquids. A significant amount of works in the area of bubble formation at submerged orifices over a wide range of design and operation parameters has appeared in the literature in last few decades. Oguz and Prosperetti (1993) investigated dynamical bubble growth on a needle. The importance of the chamber volume under a submerged orifice has been addressed by Marmur and Rubin (1976). Kumar and Kuloor (1970) published an exhaustive report on bubble formation under a wide range of operating parameters. The subject is of both academic and industrial interest and has received a continuous attention even in the present decade (Jamialahmadi et al., 2001; Li et al. 2002; Kulkarni and Joshi, 2005; Badam et al., 2007, etc.). Most of these studies can be grossly classified based on the operating parameters of the gas phase, such as the constant flow or the constant pressure. But due to variation in the gas-liquid 
systems (physical properties), type of nozzles and operating parameters (gas velocity, system pressure, etc.), the observations by many investigators are not concordant. This brings out a need to improve the observations in order to understand the bubble formation mechanism.

Multiphase flows in microfluidic devices have recently received much attention because of the foreseeable advantages that unique microscale properties could offer with regard to enhanced heat and mass transfer efficiency, reduced axial dispersion, and smaller sample volumes. In order to realize these benefits, a good understanding of the complex multiphase flow behavior in microfluidic devices must be developed. Formation of bubbles serves various applications in industrial processes such as the generation of biogas bubbles by anaerobic sludge granules in a bioreactor (Zhang et al., 2012), bubble nucleation in polymer devolatization processes (Frank et al., 2007), two-phases micro-mixing (Garstecki et al., 2006), fluorinations (Chambers et al., 2001), hydrogenations (Kobayashi et al., 2004), biochemical reactions such as DNA analysis (Burns et al., 1998), micro-channel heat exchangers (Qu and Mudawar, 2002), materials synthesis (Yen et al., 2005; Zhang et al., 2006), drug discovery (Dittrich and Manz, 2006).

The two-phase flow characteristics in microchannels are determined by the flow conditions, the channel geometry and the properties of both fluids (Waelchli and Rohr, 2006). The bubbly flow is characterized by the formation of single spherical bubbles with bubble lengths smaller than, or equal to the channel width. Increasing the gas flowrate causes the coalescence of small bubbles leading to cylindrical bubbles separated from the wall by a thin liquid film, this regime is known as slug. Generally, bubbly flow appears at high liquid velocities and low gas velocities and slug flow occurs at intermediate gas and liquid velocities while at high gas 
velocities annular flow usually prevails. In this study experiments are mainly focused on the segmented gas-liquid flows, i.e., bubbly and slug regimes.

The most popular geometries for the production of dispersed phases are T-junctions (Fu et al., 2010; Garstecki et al., 2006; van der Graaf et al., 2006; Xu et al., 2006; Guillot and Colin, 2005; Tice et al., 2003; Nisisako et al., 2002; Thorsen et al., 2001) and flow-focusing devices (Cubaud et al., 2005; Garstecki et al., 2005; Anna et al., 2003; Ganan-Calvo and Gordillo, 2001). Garstecki et al. (2005) used the flow-focusing device with a small orifice to generate monodispersed bubbles. They found that the bubble formation was due to the pressure gradient and the breakup could be controlled by the flowrate of the continuous liquid phase. Cubaud and Ho (2004) studied the formation of bubbles in square micro-channels. The bubbles were generated in a cross-shaped mixing section. Theses authors reported that the breakup mechanism in their device could be understood as the competition between the pressure drops in the gas and liquid phases respectively.

In order to gain more insight into the bubble breakup in such microfluidics devices, liquid flow field velocities have been investigated using $\mu$-PIV technique. The $\mu$-PIV technique was successfully used to characterize single-phase flow in microfluidics T-junctions (Lindken et al., 2006) and segmented multiphase flows in labs-on-chips. The $\mu$-PIV studies in the literature mainly deal with the flow or the formation in one channel and very few papers were devoted to the velocity flow field around a forming bubble. Velocity fields obtained by $\mu$-PIV at bubble formation have been reported for a T-junction (Fu et al., 2010; Van Steijn et al., 2007). To our best knowledge, there are few studies for the flow-focusing geometry. It is worthy noting that for both scales, only very few papers were devoted to the velocity profile around a forming bubble. 
For many industrial applications, it is essential to be able to predict the geometric features of the flow, such as bubble and slug length. Several correlations were proposed to determine the characteristics of the bubble (length or volume). Ganan-Calvo (1998) proposed a correlation for jet flow; Ganan-Calvo and Gordillo (2001) studied a cross flow-focusing mixer and proposed a correlation between the bubble length and the flowrate ratios in the absence of physical properties of the phases. Cubaud et al. (2005) showed that the length of the produced confined bubbles obeys a law based on the channel size and the liquid volume fraction. Garstecki et al. (2006) studied a cross flow micro-mixer and also developed a simple correlation between the flowrate ratio and the length of the bubble. To our knowledge, no correlation based on the bubble volume or on the physical properties of the liquid phase was proposed, and the existing correlations were always based on a single geometry of micromixer.

The effect of the micromixer geometry was investigated by Haverkamp et al. (2006). The authors designed two mixing geometries, namely, the "T-type" and the "smooth" mixers and studied the air-water flows in both mixers. They reported that the breakup by pressure gradient was only observed in the T-type mixer, while the jet instability was the unique mechanism for bubble formation in the smooth mixer. Fan et al. (2007) studied two types of mixer geometries including the cross-shape and the converging shape channels. The bubble shape and size and the formation mechanism were investigated for different flowrates. These authors compared simulated data with experimental results based on dimensionless numbers and generally obtained a good agreement. Different flow regimes with different bubble shapes were found depending on the capillary number of the flow. The simulated data confirmed that the breakup was induced by the pressure difference in both phases. The geometry of the mixing section was also observed to have an impact on the size of the gas and liquid slugs, 
but no experimental quantification of bubble length or volume and no velocity flow field were presented.

In the present work, the emphasis is given to the formation of bubbles in micro- and macroreactors. Since the most important forces in multiphase flows are the inertial force, viscous force, and interfacial force, the goal of our study is to understand the relative importance of these forces at different scales of reactor in order to gain more insight into the bubble formation. PIV and $\mu$-PIV techniques and a high-speed camera were employed for these studies leading to new features in this domain.

\section{Experimental setup}

\section{Macroscopic scale}

The experiments were conducted in a square Altuglas column (inner dimensions: $0.1 \mathrm{~m}$ width, $0.5 \mathrm{~cm}$ high) filled with aqueous phases. The gas bubbles were generated through a submerged orifice of diameter varying from 1 to $4 \times 10^{-3} \mathrm{~m}$ located at the centre of the bottom section of the column. An electronic valve of rapid response controlled by a personal computer permitted the injection of bubbles of determined volume at desired injection interval. In these experiments, air bubbles were always generated individually. All experiments were carried out at constant temperature of $293 \mathrm{~K}$. The visualization of the phenomenon was realized by a high-speed digital video camera CamRecord600 (Optronis GMBH, Germany) at a rate of 1000 images per second, for record grey valued images with a size of $1280 \times 1024$ pixels. The light was provided by an indirect $800 \mathrm{~W}$ halogen which 
enlightened the column via indirect lighting on a white screen placed behind the bubble column. The image sequences obtained were then analyzed in order to calculate the position, the velocity and the bubble drain. Instantaneous velocity fields around a rising bubble were measured (Fig. 1) using a Particle Image Velocimetry (PIV) device (Dantec Dynamics, Denmark). Illumination sheets were generated by two pulsed Nd-YAG LASERS (SOLO-I-15 PIV New Wave Research, USA) arranged side-by-side and crossed the vertical symmetry axis of the bubble. The energy produced by this source was $2 \times 15 \mathrm{~mJ}$. These green lasers with a wavelength of $532 \mathrm{~nm}$ had an emission duration of 8 to $10 \mathrm{~ns}$. The time interval between two consecutive illuminations ranged from less than one microsecond to a few milliseconds. The $\mathrm{Nd}-$ Yag lasers were also designed to ensure a sequence of illumination at a frequency of 15 Hz. The laser beams crossed first a cylindrical lens and obtained laser sheets of strong light intensity and low thickness $\left(2.5 \times 10^{-3} \mathrm{~m}\right.$ maximum $)$. They were focused and superposed on one zone of measurement.

The size of the seeding particle has to be chosen so that the particles follow correctly the flow and produce a sufficient light to make the recording possible and minimize the errors of measurements. Generally, diameters of particles going from 10 to 50 micrometers were used for liquids. Seeding particles used in this study were composed of silvered glass microspheres of size going from 10 to 30 micrometers (average diameter of 15 microns) and of a density of $1400 \mathrm{~kg} \cdot \mathrm{m}^{-3}$. The camera, placed perpendicular to the laser sheets, took two successive images at the maximum intensity of the laser impulse. These images were divided into a few thousands of small interrogation areas of $16 \times 16$ pixels. A cross-correlation was then performed between the corresponding interrogation areas. The liquid flow field as well as the bubble rise velocity were thus obtained. When the flow was correctly inseminated, the measurement errors of the measured velocities were less than $5 \%$. 
From these experiments, one can determine the instantaneous bubble rise velocity at different positions in the column as well as its terminal rise velocity $U$. Due to the relatively high value of the viscosity of both fluids, it was observed that the acceleration of a bubble after detachment was quickly absorbed by the liquid and the terminal rise regime was then reached at about $0.1 \mathrm{~m}$ above the orifice whatever the bubble volume used in this study.

\section{Microscopic scale}

The different geometries of microfluidics devices used in this study are reported in Figure 2. The micro-channels were fabricated in polymethylmethacrylate (PMMA). This flow-focusing geometry has a central channel for the gas dispersed phase flow, and two side channels for the inlet of the continuous liquid phase. Two sizes of liquid inlet and outlet channels $\left(W_{l}=600\right.$ $\mu \mathrm{m}$ and $1000 \mu \mathrm{m})$, and of gas inlet channels $\left(W_{g}=200 \mu \mathrm{m}\right.$ and $\left.500 \mu \mathrm{m}\right)$ were used. The section of the gas inlet is circular in order to avoid wetting problems, and the other sections are square to assure a better view of the flow field.

A pressurized tank of $10^{-3} \mathrm{~m}^{3}$ was used to maintain a constant pressure and to push the liquid and air streams into the micro channel with a regular flowrate of both phases. A gas flowmeter is used to determine the flowrate with precision. Images of bubbles were captured at steady state on the high-speed camera, capable of 500 frames per second at full resolution $(1280 \times 1024)$ with a microscopic objective ranging from $(\times 100)$ to $(\times 600)$. The length of the bubble was determined from an image analysis software and the volume of the bubble was calculated from the gas flowrate and the bubble formation frequency determined by the highspeed camera as follows: 


$$
V_{b}=\frac{Q_{g}}{f}
$$

Instantaneous liquid flow fields at microscale were measured by a $\mu$-PIV of DANTEC Dynamics (Denmark). The system consists of a Flowsense Dantec Camera with a 2048×2048 pixel array and a $7 \mathrm{~Hz}$ frequency. The microscope was equipped with different objectives ranging from $\times 5$ to $\times 100$. The micro-device under investigation faced the microscope and was illuminated from the back by a micro-strobe emitting at $530 \times 10^{-9} \mathrm{~m}$.

The liquid velocity was measured by tracking and evaluating the motion of tracer particles suspended in the fluid. The principle of $\mu$-PIV is reported in Fig. 3. The camera took two successive images at the maximum intensity of the micro stroboscope impulse. The acquired images of the flow were evaluated by dividing the images into a few thousands of small interrogation areas of $16 \times 16$ pixels. A cross-correlation was then applied on the interrogation areas in consecutive images with a $50 \%$ window overlap. For each interrogation area, the displacement vector was calculated from the location of the correlation peak. The velocity field is then calculated from the displacement vectors and the time chosen between the images. The depth of field of the microscope was between 10 and $40 \mu \mathrm{m}$, which means that the measurements are not realized on a plane, but on a slice of the micromixer. However, this value is negligible in comparison with the thickness of the microchannel. To obtain velocity flow fields, the seeding particles must perfectly follow the flow. Seeding should be uniform and at a reasonable concentration. The density should be similar to the studied fluid. If the tracer used is made of too small particles, Brownian motion can affect the measurements. This random motion of particles sets a lower limit to achieve $\mu$ PIV measurements. It is possible to 
estimate the influence of this Brownian motion. Eq. 2 establishes the relationship between the diffusion coefficients of a colloid $D$ and colloid properties.

$$
D=\frac{k T}{6 \pi \mu r}
$$

$T$ is the temperature; $\mu$ the viscosity of the fluid; $r$ the radius of the particle and $k$ the Boltzmann constant. This equation shows that more the radius of the particle is low more the Brownian motion will be great. The standard deviation of the random movement of a particle is given by Eq. 3:

$$
\Sigma_{p}=\Delta x_{p} \approx \sqrt{2 D \delta t}
$$

Thus, for a camera frequency of $4 \mathrm{~s}^{-1}$ and a particle diameter of $200 \times 10^{-9} \mathrm{~m}$, the random movement is estimated at $3 \times 10^{-6} \mathrm{~m} \cdot \mathrm{s}^{-1}$. The liquid velocity used in this study being few hundred $\mu \mathrm{m}$ per second, one gets an error of several percent on speed. We must therefore focus on larger particles to avoid problems due to Brownian motion. But bigger the particle is, bigger is its settling velocity. The sedimentation velocity of a particle diameter $d$ is estimated which leads to the expression:

$$
v_{p}=\frac{d^{2} g\left(\rho_{p}-\rho_{g}\right)}{18 \mu}
$$

For seeding particles of $3 \times 10^{-6} \mathrm{~m}$, the value of the sedimentation velocity becomes of the order of $1.5 \times 10^{-6} \mathrm{~m} . \mathrm{s}^{-1}$. Finally, to contain the contribution of both Brownian motion and settling velocity less than $1 \%$ of the measured velocity, the optimal size of seeding particle has to be in the range $\left[0.5-3 \times 10^{-6} \mathrm{~m}\right]$. Furthermore, the size of the geometry, viewing windows and objectives also will help to refine the value of the particle diameter. In this study, hydrophilic latex microspheres (Merck Estapor, France) with a density of $1056 \mathrm{~kg} . \mathrm{m}^{-3}$ and a mean diameter calibrated of $0.88 \times 10^{-6} \mathrm{~m}$ were used as seeding particles. These particles were small enough to follow the fluid and large enough to avoid the Brownian motion effects. 
When the flow is correctly inseminated, the measurement errors of the measured velocities are less than $5 \%$.

In this work, the experiments were performed using air as gas phase and water as liquid phase. A Rheometric Fluid Spectrometer RFS II (TA Instruments, USA) was employed to measure the rheological properties of the liquids. The surface tension and the contact angle of the liquid on PMMA surfaces were measured using a tensiometer, by the pending drop technique on a Tracker apparatus (I.T. Concept, France).

\section{Results and discussion}

The experiments were chosen to obtain quantitative information on the dynamics of bubble formation at microscale and macroscale in order to compare the experimental measurements and the correlations established for both scales.

The experimental flow fields obtained during the formation of a $180 \times 10^{-9} \mathrm{~m}^{3}$ bubble in water are shown in Fig. 4 for macroscale using an orifice of $4 \mathrm{~mm}$. The time interval chosen between two successive frames was $5 \times 10^{-3} \mathrm{~s}$. The choice of this temporal interval is very important in view of the rapidity of the physical phenomena. The time between two successive recordings was about $66 \times 10^{-3} \mathrm{~s}$, the formation duration being of $0.3 \mathrm{~s}$. At $t / t_{f}=$ 0.03 (Fig. 4a) and $t / t_{f}=0.3$ (Fig. 4b), one can observe the expansion phase of the bubble formation. An upward flow is first obtained at the front of the bubble as a result of the bubble expansion witch pushes the liquid upward (Fig 4a). As the bubble grows, the upward flow increases until the quantity of liquid moved reach a critical value and falls in the lateral side 
of the bubble front (Figs. $4 \mathrm{~b}$ and $4 \mathrm{c}$ ) and liquid circulations clearly appear with further expansion of the bubble due to mass conservation. In water or viscous solutions, bubble and velocity profiles were perfectly axissymmetric, and display neither shape or trajectory oscillations before the detachment., within the range of bubble size studied, which is shown in Fig. $4 d$ which represents the velocity profile few millisecond before the rupture $\left(t / t_{f}=0.99\right)$. The addition of the upward and downward flow lead to the formation of axissymmetric circulation loops which expand with an increase of the bubble volume. This recirculation loop due to the elongation step of the bubble creates a shear stress in the neck of the elongated bubble leading to its rupture. At $t / t_{f}=1.15$ (Fig. 4e), the formation cycle ends with the breakup of the neck of the bubble and its release into the column. The velocity field magnitude increases with the increase of the bubble velocity, and a downward flow appears in the wake of the bubble due to mass conservation and recirculation. This final flow field is in agreement with previous studies and PIV measurements of bubble motion and rising in stagnant fluids (Funfschilling and Li., 2001; Frank et al. 2006; and Dietrich et al., 2008). The measurements of flow fields could give further information about the formation mechanism. The major difficulty in applying the PIV technique to measure free surface flows in the vicinity of the bubble arises from the light reflection from the gas-liquid interface. The main forces acting on the forming bubble are the buoyancy and viscous drag, the surface tension force being negligible at macroscale.

Fig. 5 illustrates the liquid velocity fields around a bubble formed in a cross shape flowfocusing micro-mixer. At $t / t_{f}=0.05$ (Fig. 5a), the bubble starts to propagate into the main channel and does not seem to perturb the flow. At $t / t_{f}=0.3$ (Fig. 5b), the continuous fluid flow is bypassing the bubble at its formation. As the bubble fills up the cross-junction, the flow pattern in the two incoming continuous channels become distorted and confined at the 
wall of the channels. At $t / t_{f}=0.8$ (Fig. 5c), the bubble occupies almost the channel space leading to an acceleration of the liquid flow due to mass conservation. Close to the gas-liquid interface the liquid flow is accelerate due to mass conservation. As a result, relatively high liquid velocities up to four times the average velocity are obtained in the gap between the gas-liquid interface and the opposite wall of the channel. At $t / t_{f}=1$ (Fig. 5d), the formation cycle ends with the break-up of the neck of the bubble and its release into the main channel. Velocity flow fields are directed into both opposite directions where the bubble snaps. The main formation mechanism depends on the competition between two following forces: the static pressure exerted by lateral flows and surface tension force. Both the gravity (buoyancy) and shear stress are negligible.

The teardrop shape of the bubble at its detachment is fairly identical at both macro- and microscales. But the velocity profiles are not similar. Indeed, the confined configuration of microscale does not allow the formation of circulation loops at macroscale. Theses loops result in the displaced fluid under action of buoyancy forces which is not the case in microscale due to the wall effects. But at microscale, the action of buoyancy which tends to elongate the bubble is replaced by a liquid flow at microscale. Hence only qualitative comparisons between both scales may be obtained. Experiments were conduced for several operating conditions of gas flowrates, physical properties and orifice and channel sizes. About 100 bubbles were generated and investigated under each scale. The experimental results obtained at macroscale are well represented by the correlation (Eq. 5) proposed by Jamialahmadi (2001) which is shown on table 1. A new correlation has been proposed for bubble formation at microscale (Eq. 6) and a good agreement is obtained between predicted values and experimental data. Table 1 present the comparison of results obtained for both 
scales investigated, the correlations chosen to represent our results and theirs ranges of applications.

Even if the bubble shapes are similar in spite of the difference in size, the formation mechanisms are quite different. For our study at macroscale, only the gas phase is in circulation meanwhile two phases are flowing at microscale. Bubble formation is driven by buoyancy and gravity at macroscale and these forces are not present at microscale. This indicates that a quantitative comparison of the bubble formation is virtual impossible between these systems. In order to accomplish the comparison of the formation, governing forces on the bubble rupture mechanism should be the same at both scales.

To reach this goal, a macroscopic shear flow system was used in order to have the same forces. A rotating discus, controlled by a motor, was placed inside the column to generate an orthogonal flow at the formation. The velocity of this lateral flow was measured by PIV. The bubble was thus detached from the orifice under the lateral flow as shown in Table 2 . Different sizes of orifices, velocity of shear flow and physical properties were investigated. The correlation (Eq. 7) based on these results was developed with a good precision. In addition, the bubble formation obtained in a T-junction microreactor where bubbles are detached by a lateral flow, was studied in order to compare the results obtained at both macro and micro scale. The bubble formation results obtained in the T-junction are well represented by Eq. 8 developed for the air-water system. These two equations, their ranges of applications, their averages relative errors and the velocity profiles measured are represented in Table 2. 
Eqs. 7 and 8 reported in Table 2 propose the prediction of the bubble volume $\left(d_{b}\right.$ is the equivalent diameter of the bubble) after detachment in function of several dimensionless numbers (Froude number Fr, Bond number Bo and flowrate ratios $Q_{g} / Q_{l}$ ). In order to compare the bubble formation under shear flow in a T-junction, one has to consider the results for which the gravity is negligible compared to the shear force. This is noticeably the case when gas flowrates are less important than tangential liquid flowrates.

Experiment where the gas flowrate is fixed at $8.33 \times 10^{-9} \mathrm{~m}^{3} \cdot \mathrm{s}^{-1}$ with a gas-inlet of $1 \mathrm{~mm}$ at both scales systems were chosen. Air bubbles were generated in water under different conditions of water flowrate. At macroscale, bubbles were formed for a liquid velocities varying in the range $\left[0-0.2 \mathrm{~m} . \mathrm{s}^{-1}\right]$. Beyond this value, it is very difficult to capture the bubble in order to measure its volume contrary to the case of microscale where the liquid velocities are in the range $\left[0.2-0.4 \mathrm{~m} . \mathrm{s}^{-1}\right]$. For liquid velocities below $0.2 \mathrm{~m} . \mathrm{s}^{-1}$, the bubble reaches the other side of the channel and wettings problems occur at the wall making experiment irreproducible and out of the regular bubbling regime (i.e. slug or jet regime). Indeed, both scales complete each other in the range of lateral flow velocities.

Fig. 6 presents experimental values of bubble equivalent diameter at both scales with the correlated values in dashed lines. As shown previously, correlated values are in a good agreement with experimental results. Furthermore, it is worth noting that both correlations present a strong continuity between both scales. Macroscopic experiments have the interesting advantage that it is possible to measure the bubble volume without liquid flowrate. The evolution of the diameter at low liquid velocities presents first a stagnant zone, then a quick decrease with shear flow. When this force becomes more important than buoyancy force, the curves tend to an asymptotic line. As a result, bubble formation in a T-junction microreactor 
is the asymptotic regime of bubble formation under a shear flow. Furthermore, the bubble formation mechanism depends on the same forces at low gas flowrates. The junction between these scales reveals that the dominant force acting on the bubble arises from the lateral flows.

\section{Conclusion}

By means of both the visualization and the quantification of the complex bubble formation, the present work presents a first tentative to reveal the various mechanisms governing the formation from microscale to macroscale. In particular, the flow field measurements obtained by the PIV and $\mu$-PIV systems contribute to the understanding of the different steps encountered during the bubble formation and bring new information concerning the hydrodynamics around a forming bubble. Moreover, the visualization of the bubble formation could help the modelling and numerical simulation of the film rupture, which takes place in many industrial processes like emulsification, mixing or separation. Finally, global correlations for the bubble formation at both macro- and microscales were proposed to estimate the bubble volume after the detachment. Logically, these correlations are not comparable when the mechanism is not similar due to the different forces involved, for example one of the dominant parameters governing the bubble formation at microscale is the wall effects. A lateral flow must be used to make possible the multi scale comparison and small values of gas flowrate have to be considered to be able to neglect the gravity effects. Under these similar conditions, the multi-scale comparison shows a quite good agreement between correlations obtained at micro- and macroscales. These results throw new insight into the mechanisms of bubble formation at different scales, in particular the evolution of various forces due to changes in length scale. The consideration of the effect of a lateral liquid flow on the bubble formation could lead to a more accurate modelling under complex conditions 
such as the formation of a dissymmetrical bubble encountered in industrial applications due to liquid flow.

\section{Notation}

Bo Bond number $\left(B o=d^{2} \Delta \rho / \sigma\right)$

$D$ diffusion coefficient, $m^{2} . s^{-1}$

$d_{b} \quad$ equivalent diameter of bubble, $m$

$f \quad$ bubble formation frequency, $\mathrm{Hz}$

$\mathrm{Fr} \quad$ Froude number $\left(\mathrm{Fr}=u^{2} / g d\right)$

$k \quad$ Boltzmann constant, J.K $K^{-1}$

$L \quad$ length, $m$

Mo Morton number $\left(M o=g \mu^{4} / \rho \sigma^{3}\right)$

Q flowrate, $m^{3} \cdot s^{-1}$

$r \quad$ bubble radius, $m$

Re Reynolds number $(\operatorname{Re}=\rho u d / \mu)$

$T$ temperature, $K$

$t \quad$ time $(s)$

$t_{f}$ formation duration of a bubble $(s)$

$U$ bubble rise velocity, $m . s^{-1}$

$V_{b} \quad$ bubble volume, $m^{3}$

$v_{p}$ terminal falling velocity of a sphere, $m \cdot s^{-1}$

W channel width, $m$

$\mu \quad$ viscosity, Pa.s 
$\theta \quad$ mixer angle, ${ }^{\circ}$

$\theta c$ contact angle on PMMA, ${ }^{\circ}$

\section{Subscripts}

g gas

liquid

$m \quad$ mixer

max maximal

p particle

ref reference properties

\section{References}

Anna, S.L., Bontoux, N., and Stone, H.A., 2003. Formation of dispersions using "flow focusing"' in microchannels. Applied Physics Letters 82, 364-366.

Badam V. K., Buwa, V. and Durst F., 2007, Experimental investigations on regimes of bubble formation on submerged orifices under constant flow conditions. Canadian Journal of Chemical Engineering 85, 257-267.

Bashforth, F. and Adams, J.C., 1883. An attempt to test the theories of capillary action, Cambridge University Press, Cambridge, UK.

Burns, M.A., Johnson, B.N., Brahmasandra, S.N., JamesK.H., Webster, R., Krishnan, M., Sammarco, T.S, Man, P.M., Jones, D., Heldsinger, D., Mastrangelo, C.H., and Burke, D.T., 1998. An Integrated Nanoliter DNA Analysis Device. Science 282, 484-487. 
Chambers, R.D., Holling, D., Spink, R.C.H., Sandford, G., 2001. Elemental fluorine - Part 13. Gas-liquid thin film microreactors for selective direct fluorination. Lab on a Chip 1, 132137.

Cubaud, T., Ho, C. M., 2004. Transport of bubbles in square microchannels. Physics of Fluids 16, 4575-4585.

Cubaud, T., Ho, C.-M., 2004. Transport of bubbles in square microchannels. Physics of Fluids $16,4575-4585$.

Cubaud, T., Tatineni, M., Zhong, X. and Ho, C.M., 2005. Bubble dispenser in microfluidic devices. Physical Review E, 27, 037302.

Davidson, J.F., Schüler, B.O.G. 1960b. Bubble formation at an orifice in an inviscid liquid. Trans. Instn Chem. Engrs 38, 335-342.

Davidson, J.F., Schuler, B.O.G., 1960a. Bubble formation at an orifice in a viscous liquid. Trans. Instn Chem. Engrs 38, 144-154.

Dietrich, N., Poncin, S., Pheulpin, S., Li, H.Z., 2008. Passage of a bubble through a liquidliquid interface. American Institute of Chemical Engineers Journal 54, 594-600.

Dittrich, P.S., Manz, A., 2006. Lab-on-a-chip: microfluidics in drug discovery. Nature Reviews Drug Discovery 5, 210-218.

Fan, L.S., Yu, Z., Hemminger, O., 2007. Experiment and lattice Boltzmann simulation of two phase gas-liquid flows in microchannels. Chemical Engineering Science 62, 7505-7514.

Frank X., Funfschilling D., Midoux N. and Li H.Z., 2006. Bubbles in a viscous liquid: Lattice Boltzmann simulation and experimental validation, Journal Fluid Mechanics 546, 113-122.

Frank, X., Dietrich, N., Wu, J., Barraud, R., Li, H.Z., 2007. Bubble nucleation and growth in fluids. Chemical Engineering Science 62, 7090-7097. 
Fu, T., Ma, Y., Funfschilling, D., Zhu, C. and Li, H.Z., 2010. Squeezing-to-dripping transition for bubble formation in a microfluidic T-junction, Chemical Engineering Science 65, $3739-3748$

Funfschilling, D., Li, H. Z., 2001. Flow of non-Newtonian fluids around bubbles: PIV measurements and birefringence visualisation. Chemical Engineering Science, 56, 11371141.

Gaddis, E., Vogelpohl, A., 1986. Bubble formation in quiescent liquids under constant flow conditions. Chemical Engineering Science 41, 97-105.

Ganan-Calvo, A.M., 1998. Generation of steady liquid microthreads and micron-sized monodisperse sprays in gas streams. Physical Review Letters 80, 285-288.

Ganan-Calvo, A.M., Gordillo, J.M., 2001. Perfectly monodisperse microbubbling by capillary flow focusing. Physical Review Letters 87, 274501.

Garstecki, P., Fuerstman, M.J., Stone, H.A., Whitesides, G.M., 2006. Formation of droplets and bubbles in a microfluidic T-junction - scaling and mechanism of break up. Lab on a Chip, 6, 437-446.

Garstecki, P., Stone, H.A., Whitesides, G.M., 2005. Mechanism for flowrate controlled breakup in confined geometries. Physical Review Letters 94, 164501.

Gerlach D., G. Biswas, F. Durst and V. Kolobaric, 2005. Quasi-static bubble formation on submerged orifices, International Journal of Heat and Mass Transfer 48, 425-438.

Guillot, P., Colin, A., 2005. Stability of parallel flows in a microchannel after a T junction. Physical Review E 72, 066301.

Haverkamp, V., Hessel, V., Lowe, H., Menges, G., Warnier, M. J. F., Rebrov, E. V., de Croon, M. H. J. M., Schouten, J. C., Liauw, M. A., 2006. Hydrodynamics and MixerInduced Bubble Formation in Micro Bubble Columns with Single and Multiple-Channels. Chemical Engineering Technology 29, 1015-1026. 
Jamialahmadi, M., Zehtaban, M.R., Steinhagen, H.M., Sarrafi, A. and Smith, J.M., 2001. Study of Bubble Formation under Constant Flow Conditions. Trans IChemE 79A, 523532.

Kobayashi, J., Mori, Y., Okamoto, K., Akiyama, R., Ueno, M., Kitamori, T., Kobayashi, S., 2004. A Microfluidic Device for Conducting Gas-Liquid-Solid Hydrogenation Reactions. Science 304, 1305-1308.

Kulkarni, A.A. and Joshi, J. B., 2005. Bubble Formation and Bubble Rise Velocity in GasLiquid Systems: A Review. Ind. Eng. Chem. Res. 44, 5873-5931.

Kumar, R. and Kuloor, N.R, 1970. The formation of bubbles and drop. Adv. Chem. Eng., Academic Press, N.Y.

Li, H.Z., Mouline, Y. and Midoux, N., 2002. Modelling the bubble formation dynamics in non-Newtonian fluids, Chemical Engineering Science 57, 339-346.

Lindken, R., Westerweel, J., Wieneke, B., 2006. Stereoscopic micro particle image velocimetry. Experiments in Fluids 11, 161-171.

Marmur, A., Rubin, E.A., 1976. Theoretical model for bubble formation at an orifice submerged in an inviscid liquid. Chemical Engineering Science 31, 453-463.

Nisisako, T., Torii, T., Higuchi, T., 2002. Droplet formation in a microchannel network. Lab on a Chip, 2, 24-26.

Oguz, H.N. and Prosperetti, A. 1993. Dynamics of bubble growth and detachment from a needle. Journal Fluid Mechanics 257, 111-145.

Qu, W., Mudawar, I., 2002. Experimental and numerical study of pressure drop and heat transfer in a single-phase micro-channel heat sink. International Journal of Heat and Mass Transfer 45, 2549-2565.

Tate, T., 1864. On the magnitude of a drop of liquid formed under different circumstances. Philosophical Magazine 4, 176-185. 
Thorsen, T., Roberts, W. R., Arnold, F. H., Quake, S. R., 2001. Dynamic pattern formation in a vesicle-generating microfluidic device. Physical Review Letters 86, 4163-4166.

Tice, J. D., Song, H., Lyon, A. D., Ismagilov, R. F., 2003. Formation of droplets and mixing in multiphase microfluidics at low values of the Reynolds and the capillary number. Langmuir 19, 9127-9133.

van der Graaf, S., Nisisako, T., Schroe, C.G.P.H., van der Sman, R.G.M., Boom, R. M., 2006. Lattice Boltzmann Simulations of Droplet Formation in a T-Shaped Microchannel. Langmuir, 22, 4144-4152.

Waelchli, S., von Rohr, R., 2006. Two-phase flow characteristics in gas-liquid micro reactors. International Journal of Multiphase Flow 32, 791-806.

Xu, J.H., Li, S.W., Wang, Y.J., Luo, G.S., 2006. Controllable gas-liquid phase flow patterns and monodisperse microbubbles in a microfluidic T-junction device. Applied Physics Letters 88, 133506.

Yen, B.K.H., Gunther, A., Schmidt, M.A., Jensen, K.F., 2005. A microfabricated gas-liquid segmented flow reactor for high-temperature synthesis: the case of CdSe quantum dots. Angewandte Chemie International, 44, 5447-5451.

Zhang, H., Tumarkin, E., Peerani, R., Nie, Z., Sullan, R. M. A., Walker, G.C., Kumacheva, E., 2006. Microfluidic production of biopolymer microcapsules with controlled morphology. Journal of the American Chemical Society 128 12205-12210.

Zhang, J.B., Wu, J., Poncin, S., Hamelin, M. and Li, H.Z., 2012. A microscale study of anaerobic biogas production under various hydrodynamic conditions, Environmental Science and Technology, DOI: 10.1021/es3013722. 


\section{Caption of tables}

Table 1. Comparison of the bubble formation at macro and microscales.

Table 2. Comparison of the bubble formation under a lateral shear flow for macro and microscales.

\section{Caption of figures}

Figure 1. Experimental setup.

Figure 2. Illustration of the micro fluidic chip used to generate micro bubbles. Cross shape ( $\theta$ $\left.=180^{\circ}\right)$

Figure 3. Micro-Particle Image Velocimetry principle ( $\mu$-PIV). $50 \times 50 \mu \mathrm{m}$ windows.

Figure 4. Sequence of PIV velocity fields around a growing and detaching bubble of $150 \times 10^{-9}$ $\mathrm{m}^{3}$ in stagnant fluid. $t_{f}=0.260 \mathrm{~s}$. (a) $t / t_{f}=0.03$; (b) $t / t_{f}=0.3$; (c) $t / t_{f}=0.7$; (d) $t / t_{f}=0.99$; (e) $t / t_{f}$ $=1.15 . Q_{g}=1.5 \times 10^{-6} \mathrm{~m}^{3} \cdot \mathrm{s}^{-1}$.

Figure 5. Velocity flow field measured in the middle of the channel by the $\mu$-PIV system for a $10^{-9} \mathrm{~m}^{3}$ bubble in a cross flow-focusing mixer. Gas inlet phase diameter is $200 \mu \mathrm{m}$, liquid inlet and outlet channel size are $1000 \mu \mathrm{m}$, the liquid is pure water (a) $t / t_{f}=0.05$; (b) $t / t_{f}=0.3$ (c); $t / t_{f}=0.8 ;(\mathrm{d}) t / t_{f}=1 . Q_{g}=Q_{l}=10^{-8} \mathrm{~m}^{3} \cdot \mathrm{s}^{-1}$. 
Figure 6. Comparison of both correlations at macroscale and microscale for $d_{0}=W=1 \mathrm{~mm}$ for the formation of air bubble in water under a lateral shear flow. $Q_{g}=10^{-8} \mathrm{~m}^{3} \cdot \mathrm{s}^{-1}, U_{g}=0.01$ $\mathrm{m} \cdot \mathrm{s}^{-1}$ 